\title{
Gebelerde Fiziksel Aktivite ve Yaşam Kalitesi Arasındaki İlişki
}

\section{The Relation between Physical Activity and Quality of Life in Pregnancy}

Öz

Amaç: Bu çalışmada gebe kadınlarda fiziksel aktivite ve yaşam kalitesi seviyelerini belirlemek ve bunlar arasındaki ilişkiyi incelemek amaçlanmıştır.

Gereç ve Yöntemler. Bu çalışmaya gebelik nedeniyle başvuran toplam 210 kadın dahil edildi. Çalışmada kadınların sosyodemografık özellikleri demografık bilgi formu ile toplandı. Kadınların fıziksel aktivite seviyeleri Uluslararası Fiziksel Aktivite Anketi-Kısa Formu ile, yaşam kaliteleri ise Nottingham Sağlık Profili ile değerlendirildi.

Bulgular. Fiziksel aktivite seviyesi ile Nottingham Sağlık Profili toplam, enerji seviyesi, sosyal izolasyon ve uyku alt parametreleri arasında negatif yönde düşük düzeyde anlamlı bir korelasyon vardı (toplam için $r=-0,19 ; p=0,007$; enerji seviyesi için $r=-0,17 ; p=0,01$; sosyal izolasyon için $r=-0,16 ; p=0,01$ ve uyku için $r=-0,14 ; p=0,03$ ). Gebelik trimesterlerine göre yaşam kalitesi ve fıziksel aktiviteleri karşılaştırıldığında Nottingham Sağlık Profıli toplam, emosyonel reaksiyonlar sosyal izolasyon, fiziksel aktivite parametreleri ile Uluslararası Fiziksel Aktivite Anketi-Kısa Formu değerlerinde anlamlı fark bulundu $(p<0,05)$

Tartışma ve Sonuç: Çalışmamızda fiziksel aktivite seviyesi ile yaşam kalitesi arasında negatif yönde ilişki olduğu sonucuna varıldı. Daha geniş örneklemler üzerinde, gebelerde fiziksel aktiviteyi değerlendiren gebeliğe özgü bir fiziksel aktivite anketi kullanılarak gerçekleştirilecek çalışmalara ihtiyaç olduğu düşüncesindeyiz.

Anahtar Sözcükler: gebelik; yaşam kalitesi; fiziksel aktivite

\section{Abstract}

Aim: In this study, we aimed to determine physical activity and quality of life levels of pregnant women and to examine relations between them

Materials and Methods: A total of 210 women who applied due to pregnancy were included in this study. Sociodemographic characteristics of the women were obtained by using the demographic information form. The International Physical Activity Questionnaire-Short Form was used to investigate the women's physical activity levels and the Nottingham Health Profile to assess their quality of life.

Results: There was a low negative correlation between physical activity level and the Nottingham Health Profile total, energy level, social isolation and sleep subparameters (for total $r=$ $-0.19, p=0.007$; for energy level $r=-0.17, p=0.01$; for social isolation $r=-0.16, p=0.01$; and for sleep $r=-0.14, p=0.03$ ). When quality of life and physical activity were compared on the basis of gestational trimester, a significant difference was observed in the Nottingham Health Profile total, emotional reactions, social isolation and physical activity parameters and the International Physical Activity Questionnaire-Short Form values $(p<0.05)$

Discussion and Conclusion: In this study we found a negative relation between physical activity and quality of life levels. We are in the opinion that there is need to perform studies on larger samples by using a physical activity questionnaire developed specifically to assess physical activity in pregnancy.

Keywords: pregnancy; quality of life; physical activity
Özlem Çınar Özdemir ${ }^{1}$

Mahmut Sürmeli', Alp Özel' İdil Esin Yavuz², Ata Topçuoğlu³, Handan Ankaralı ${ }^{4}$

Abant Izzet Baysal Üniversitesi K. D. Fizik Tedavi ve Rehabilitasyon Yüksekokulu

Özel Natomed Hastanesi

Abant İzzet Baysal Üniversitesi Tıp Fakültesi Kadın Hastalıkları ve Doğum Anabilim Dalı

4 İstanbul Medeniyet Üniversitesi. Tıp Fakültesi Biyoistatistik ve Tıp Bilişim Anabilim Dalı

Gelis Tarihi /Received : 06.03.2017 Kabul Tarihi /Accepted: 01.04.2017

DOI: DOI: 10.21673/anadoluklin.296544

Sorumlu Yazar/Corresponding Author Yrd. Doç. Dr. Özlem Cınar Özdemir Abant İzzet Baysal Üniversitesi Kemal Demir Fizik Tedavi ve

Rehabilitasyon Yüksekokulu Gölköy Kampüsü, Bolu, Türkiye

E-mail: ozlemcinar314@hotmail.com 


\section{Gíiş}

Fiziksel aktivite Dünya Sağlık Örgütü tarafından iskelet kaslarının kasılmasıyla ortaya çıkan herhangi vücut hareketi olarak tanımlanmıştır (1). Düzenli ve yeterli miktarda fiziksel aktivitenin vücut kompozisyonu, kassal ve kardiyorespiratuvar uygunluk, fonksiyonel sağlık ve psikolojik iyilik halinin gelişmesi; hipertansiyon, felç, diyabet, koroner kalp hastalığı, gögüs ve kolon kanseri riskinin azaltılması ve yaşam kalitesinin iyileştirilmesi gibi fiziksel fonksiyon ve psikolojik parametreler üzerinde olumlu etkisi vardır $(1,2)$.

Sağlık için pek çok faydası bulunmasından dolayı düzenli fiziksel aktivite gebe kadınlar için de tavsiye edilmektedir (3). Gebelik sürecinde anne ve çocuk sağlığındaki öneminin yanı sıra (4); maternal, fetal ve neonatal olumsuz sonuçlarla karşılaşma riskini de azaltabilir $(5,6)$. Ayrıca, kilo kontrolündeki rolüne ek olarak gestasyonel diyabet ve hipertansiyon riskini $(7,8)$, bel ağrısını, depresyon belirtilerini azaltır (9) ve gebe kadınların ruh halinde gelişme sağlar (10). Yapılan epidemiyolojik çalışmalarda gebelik sürecinde fiziksel olarak daha aktif olan kadınların kronik kas-iskelet sistemi problemleri, gestasyonel diyabet ve hipertansiyon (11) ile üriner inkontinans gibi durumlar açısından daha düşük risk altında bulunduğu ve gebelikteki değişikliklere adaptasyon açısından daha iyi durumda oldukları belirtilmiştir (12).

Sağlık açısından kanıtlanan pek çok etkisine rağmen, gebe kadınlarda fiziksel aktivitenin yetersiz düzeylerde olduğu belirtilmektedir (13). Çalışmalar pek çok kadının gebe kaldıktan sonra fiziksel aktivite düzeylerini azalttığını göstermektedir $(14,15)$. Fiziksel aktivite düzeylerindeki azalmanın trimestere göre değiştiği çalışmalarda belirtilmiştir. Azalmanın iş, rekreasyonel ve ortalama fiziksel aktivite seviyelerine yansıdığını (16,17); özellikle ikinci ve üçüncü trimesterde daha fazla düşüş gerçekleştiğini belirten çalışmalar bulunmaktadır (18). Bu azalmanın hem fiziksel aktivite çeşitliliğinde hem de devam ettirilen aktivitelerin sıklık ve süresinde gözlendiği belirtilmektedir (19). Bunun yanı sıra ilk trimesterde, ikinci ve üçüncü trimestere göre daha düşük fiziksel aktivite düzeyi gözlendiğini belirten çalışmalar da mevcuttur $(20,21)$.

Gebenin fonksiyonel ve ruhsal durumu gebelik döneminde değişiklik gösteren birtakım hormonal ve fiziksel değişimlerden etkilenir ve bu durum yaşam kalitesinde de değişikliğe sebep olabilmektedir (22). Gebelikte yaşanan uyku bozukluğu, yorgunluk ve kilo alımı gibi fiziksel sorunların, duygusal değişimlerin ve bunlar neticesinde ortaya çlkan aktivite kısıtlılığ1nın genel yaşam kalitesinde azalmaya sebep olduğu ve bu azalmanın gebeliğin ilerleyen dönemlerinde arttığ göze çarpmaktadır (23).

Yapılan literatür araştırmaları doğrultusunda, gebelerin farklı trimesterlerde gebelikle ilgili durumlar nedeniyle fiziksel aktivite seviyelerinde ve yaşam kalitelerinde değişimler yaşadıkları belirtilmektedir. Ancak ülkemizde gebeler üzerinde yapılan çalışmaların genelde gebelerin sosyodemografik özellikleri, gebelikte depresyon-anksiyete düzeyleri ve gebelik döneminde yaşanan fiziksel ve psikolojik değişiklikler ile ilgili olduğu görülmektedir. Gebelerin farklı trimesterlerde fiziksel aktivite ve yaşam kalitesi seviyelerinde değişimlerin olduğu varsayımından yola çıkılarak planlanan bu çalışmanın amacı, farklı gebelik dönemlerinde gebelerin fiziksel aktivite seviyelerini belirlenmek ve fiziksel aktivite ile yaşam kalitesi arasındaki ilişkiyi değerlendirmektir.

\section{GEREÇ VE YÖNTEMLER}

Gebe kadınlarda, fiziksel aktivite ve yaşam kalitesi arasındaki ilişkiyi incelemek amacını taşıyan bu çalışmaya Abant İzzet Baysal Üniversitesi Kadın Hastalıkları ve Doğum Anabilim Dalı’na başvuran toplam 210 gebe kadın dahil edildi.

Kalp hastalı̆̆ı, diyabeti, hipertansiyonu olan kadınlarla, 16 yaş altı ve 40 yaş üstü kadınlar çalışma dışı bırakıldı. Bu çalışma için, Abant İzzet Baysal Üniversitesi Sosyal Bilimler ve İnsan Araştırmaları Etik Kurulu'ndan etik kurul onayı alındı (Protokol No: 2015/54).

Çalışma için uygun bulunan kadınlara çalışma hakkında bilgi verildi ve bilgilendirilmiş onamları alındı. Değerlendirmede ad, soyad, telefon, sigara kullanımı gibi kişisel bilgileri, yaş, obstetrik hikaye, gebelik haftası, öğrenim durumu gibi demografik ve klinik bilgileri içeren bilgi formu, yaşam kalitesi ve fiziksel aktivite anketleri kullanıld. Her iki veri toplama aracı araştırmacılar tarafından katılımcılarla gerçekleştiri- 
Tablo 1. Kadınların fiziksel ve demografik özellikleri

\begin{tabular}{|c|c|c|}
\hline & $\begin{array}{c}\mathrm{X}+\mathrm{SS} \\
(\mathrm{n}=210)\end{array}$ & \\
\hline Yaş (y1l) & $27,33 \pm 4,74$ & \\
\hline Boy $(\mathrm{cm})$ & $161,93 \pm 5,83$ & \\
\hline Kilo (kg) & $67,32 \pm 11,35$ & \\
\hline \multirow[t]{2}{*}{ VKİ $\left(\mathrm{kg} / \mathrm{m}^{2}\right)$} & $25,61 \pm 4,39$ & \\
\hline & $\mathbf{n}$ & $\%$ \\
\hline \multicolumn{3}{|l|}{ Eğitim düzeyi } \\
\hline İlköğretim & 52 & 25 \\
\hline Lise & 132 & 63 \\
\hline Üniversite & 26 & 12 \\
\hline \multicolumn{3}{|l|}{ Doğum sayısı } \\
\hline 0 & 112 & 53,3 \\
\hline 1 & 66 & 31,4 \\
\hline$\geq 2$ & 32 & 15,3 \\
\hline \multicolumn{3}{|l|}{ Gebelik dönemi } \\
\hline Birinci trimester & 53 & 25,2 \\
\hline İkinci trimester & 92 & 43,8 \\
\hline Üçüncü trimester & 65 & 31 \\
\hline
\end{tabular}

*VKİ: Vücut kitle indeksi

Tablo 2. Kadınların yaşam kalitesi ve fiziksel aktivite düzeyleri

\begin{tabular}{lcc}
\hline & ortanca & $\% 25-75$ \\
\hline NSP (toplam) & 129 & $67-229$ \\
\hline NSPA & 12 & $0-30$ \\
\hline NSPFA & 27 & $10-45$ \\
\hline NSPES & 36 & $0-76$ \\
\hline NSPSI & 0 & $0-30$ \\
\hline NSPER & 0 & $0-17$ \\
\hline NSPU & 26 & $0-48$ \\
\hline $\begin{array}{l}\text { UFAA-KF } \\
\text { (METxdk/hafta) }\end{array}$ & 397 & $0-1074$ \\
\hline & $\mathbf{n}$ & $\%$
\end{tabular}

Fiziksel aktivite

seviyesi

\begin{tabular}{lcc}
\hline İnaktif & 128 & 61 \\
\hline Minimal aktif & 66 & 31 \\
\hline Çok aktif & 16 & 8
\end{tabular}

* NSP: Nottingham Sağlık Profili, NSPA: Nottingham Sağlık Profili-Ağrı, NSPFA: Nottingham Sağlık Profili-Fiziksel Aktivite, NSPES: Nottingham Sağllk Profili-Enerji Seviyesi, NSPSİ: Nottingham Sağlık Profili-Sosyal İzolasyon, NSPER: Nottingham Sağlık Profili-Emosyonel Reaksiyonlar, NSPU: Nottingham Sağlık Profili-Uyku, UFAA-KF: Uluslararası Fiziksel Aktivite Anketi-Kısa Form, MET: Metabolik eşdeğer. len yüz yüze görüșmelerde kullanıldı ve toplanan veriler araştırmacılar tarafından kaydedildi.

Yaşam kalitesini değerlendirmek için Türkçe geçerliliği Küçükdeveci ve ark. (24) tarafından yapılan Nottingham Sağlık Profili (NSP) kullanıldı. NSP, kişinin algıladığı sağlık problemlerini ve bu problemlerin normal günlük aktiviteleri etkileme düzeyini ölçen bir genel yaşam kalitesi anketidir. Anket, 38 maddeden oluşur ve sağlık statüsü ile ilgili altı boyutu değerlendirir: enerji (3 madde), ağrı (8 madde), emosyonel reaksiyonlar (9 madde), uyku (5 madde), sosyal izolasyon (5 madde) ve fiziksel aktivite (8 madde). Sorulara "Evet" veya "Hayır" șeklinde cevap verilir. Her bölüme 0 ile 100 arasında bir puanlama yapılır. Her bölüm için "0" en iyi sağlık durumunu, "100" en kötü sağllk durumunu gösterir.

Çalışmamıza katılan kadınların fiziksel aktivite seviyeleri Uluslararası Fiziksel Aktivite Anketi'nin kısa formu (UFAA-KF) kullanılarak değerlendirildi. UFAA-KF Dünya Sağlık Örgütü (DSÖ) ve Amerika Birleşik Devletleri Hastalık Kontrol ve Önleme Merkezleri’nin desteğiyle geliștirilmiş ve Türkçe geçerlilik-güvenilirlik çalışması Türkiye'de Sağlam ve ark. (25) tarafından yapılmıştır. Bireylerin hafif, orta ve şiddetli aktivitelerde harcadıkları zaman ve oturma süreleri hakkında bilgi vermektedir. Aktiviteler değerlendirilirken ölçüt her aktivitenin bir defada en az 10 dakika yapılmasıdır. Her aktivite düzeyi için MET değeri (metabolik eşdeğer) gün ve dakika çarpılarak "MET-dk/hafta" skoru elde edilir. Elde edilen skor fiziksel aktivite yapmayan (MET $\leq 600$ enerji düzeyi), yetersiz aktivite düzeyi olan (MET $=600-3000$ enerji düzeyi) ve yeterli aktivite düzeyi olan (MET $\geq 3000$ enerji düzeyi) şeklinde sınıflandırılmaktadır. Her fiziksel aktiviteye ne kadar enerji harcandığının belirlenmesinde ise her aktivitenin dakika cinsinden haftalık süresi ile UFAA-KF için belirlenen MET değerleri çarpılmıştır. Sonucunda bireylerin hafif, orta, şiddetli aktivite düzeyi ve toplam aktivite düzeyinde harcadıkları enerjiler hesaplanmıştır.

\section{İstatistiksel Analiz}

Elde edilen ölçümlere ait tanımlayıcı değerler ortalama, ortanca değer, standart sapma, sayı ve \% frekanslar olarak hesaplanıp tablolar halinde verildi. Sayısal özelliklerin her bir grupta normal dağılım gösterip 
Tablo 3. Kadınların gebelik trimesterlerine göre fiziksel aktivite puanlarının dağılımı

\section{Gebelik Dönemi}

I. Trimester II. Trimester III. Trimester

\begin{tabular}{lcccccc}
\hline Fiziksel aktivite düzeyi & $\mathrm{n}$ & $\%$ & $\mathrm{n}$ & $\%$ & $\mathrm{n}$ & $\%$ \\
\hline İnaktif & 33 & 62 & 51 & 55 & 44 & 68 \\
\hline Minimal aktif & 18 & 34 & 29 & 32 & 19 & 29 \\
\hline Çok aktif & 2 & 4 & 12 & 13 & 2 & 3 \\
\hline
\end{tabular}

göstermediği Kolmogorov-Smirnov testi ile incelendi. En az biri normal dağılmayan veya ordinal olan değişkenler arası ilişkiler için korelasyon katsayıları ve istatistiksel anlamlılıklar Spearman korelasyon katsayısı ile hesaplandı. Grupların karşılaştırılmasında tek yönlü varyans analizi kullanıldı. İstatistik anlamlılık düzeyi $\mathrm{p} \leq 0,05$ alındı ve hesaplamalarda PASW (Ver. 18) kullanıldı.

\section{BULGULAR}

$\mathrm{Bu}$ çalışmaya yaş ortalamaları $27,33 \pm 4,74$ olan 210 kadın dahil edildi. Kadınların 112'sinin $(\% 53,3)$ hiç doğum yapmadığı, 66'sının $(\% 31,4)$ bir kez, 32'sinin $(\% 15,3)$ ise iki ve daha fazla kez doğum yaptığı saptand. Kadınların 53'ü $(\% 25,2)$ gebeliğin birinci trimesterinde, 92'si $(\% 43,8)$ ikinci trimesterinde ve 65 'i $(\% 31)$ ise üçüncü trimesterindeydi (Tablo 1).

Çalışmaya katılan kadınların yaşam kaliteleri incelendiğinde NSP toplam puan, ağrı, fiziksel aktivite, enerji seviyesi, sosyal izolasyon, uyku ve emosyonel reaksiyonlar alt skalaları puanlarının ortancalarının sirasiyla 129 puan, 12 puan, 27 puan, 36 puan, 0 puan ve 26 puan olduğu görüldü. Olguların haftalık fiziksel aktivite puanlarının ortancası ise, 397 METxdk olarak hesaplandı. UFAA-KF puanlarına göre olguların \%61'i "inaktif," \%31'i "minimal aktif" ve \%8'i "çok aktif" olarak fiziksel aktivite seviyelerine göre sınıflandırıldı (Tablo 2). Ayrıca kadınların fiziksel aktivite düzeyleri gebelik dönemlerine göre de sınıflandırıldı (Tablo 3).

Kadınların fiziksel aktivite puanı ile NSP toplam ve NSP alt parametreleri arasında korelasyon bulunamad1. İnaktif, minimal aktif ve çok aktif fiziksel aktivite seviyesi ile NSP toplam, enerji seviyesi, sosyal izolasyon ve uyku alt parametreleri arasında negatif yönde düşük düzeyde anlamlı bir korelasyon vardı (NSP toplam için $r=-0,19 ; p=0,007$; NSP enerji seviyesi için $r$ $=-0,17 ; \mathrm{p}=0,01 ; \mathrm{NSP}$ sosyal izolasyon için $\mathrm{r}=-0,16$; $\mathrm{p}=0,01$ ve NSP uyku parametresi için $\mathrm{r}=-0,14 ; \mathrm{p}=$ 0,03) (Tablo 4).

Gebelik trimesterlerine göre yaşam kalitesi ve fiziksel aktivite karşılaştırıldığında NSP toplam; NSP emosyonel reaksiyonlar; NSP sosyal izolasyon, NSP fiziksel aktivite ile UAFA-KF değerlerinde anlamlı fark bulundu $(\mathrm{p}<0,05)($ Tablo 5$)$.

\section{TARTISSMA}

Gebelerin fiziksel aktivite ve yaşam kalitesi düzeylerini belirlemek ve aralarında ilişki olup olmadığını incelemek amacıyla yapılan bu çalışmada, kadınların toplam fiziksel aktivite puanı ile NSP toplam ve NSP alt parametreleri arasında ilişki bulunmadı. Aktivite düzeylerine göre fiziksel aktivite seviyesi ile NSP toplam, enerji seviyesi, sosyal izolasyon ve uyku alt parametreleri arasında negatif yönde düşük düzeyde ilişki olduğu sonucuna varıldı. Çalışmada ayrıca gebelik trimesterlerine göre kadınların yaşam kalitesi puanları ve fiziksel aktivite düzeyleri incelendiğinde gebeliğin ilk trimesterinden üçüncü trimestere ilerledikçe yaşam kalitesi düzeylerinde azalma olduğu belirlendi.

Literatürde gebelik dönemlerinde fiziksel aktivite seviyesindeki zamanla ortaya çıkan değişimleri in-

Tablo 4. Yaşam kalitesi ve fiziksel aktivite seviyesi arasındaki ilişki

\begin{tabular}{|c|c|c|}
\hline & $\begin{array}{c}\text { UFAA-KF } \\
\text { r(p) }\end{array}$ & $\begin{array}{l}\text { Fiziksel aktivite } \\
\text { seviyesi } \mathbf{r}(\mathbf{p})\end{array}$ \\
\hline NSP (toplam) & $0,00(0,9)$ & $-0,19(0,00)$ \\
\hline NSPA & $-0,01(0,85)$ & $-0,11(0,08)$ \\
\hline NSPFA & $-0,06(0,34)$ & $-0,04(0,48)$ \\
\hline NSPES & $0,03(0,57)$ & $-0,17(0,01)$ \\
\hline NSPSE & $0,00(0,89)$ & $-0,16(0,01)$ \\
\hline NSPER & $-0,00(0,89)$ & $-0,03(0,66)$ \\
\hline NSPU & $0,04(0,53)$ & $-0,14(0,03)$ \\
\hline \multicolumn{3}{|c|}{$\begin{array}{l}\text { * } \mathrm{p}<0,05 \text {. r: Spearman korelasyon katsayısı. UFAA-KF: Uluslara- } \\
\text { rası Fiziksel Aktivite Anketi-Kısa Form, NSP: Nottingham Sağlık } \\
\text { Profili, NSPA: Nottingham Sağlık Profili-Ağrı, NSPFA: Notting- } \\
\text { ham Sağlık Profili-Fiziksel Aktivite, NSPES: Nottingham Sağlık } \\
\text { Profili-Enerji Seviyesi, NSPSI: Nottingham Sağlık Profili-Sosyal } \\
\text { İzolasyon, NSPER: Nottingham Sağlık Profili-Emosyonel Reaksi- } \\
\text { yonlar, NSPU: Nottingham Sağlık Profili-Uyku. }\end{array}$} \\
\hline
\end{tabular}


Tablo 5. Gebelik trimesterlerine göre yaşam kalitesi ve fiziksel aktivite karşılaştırması

\begin{tabular}{|c|c|c|c|c|}
\hline & I. Trimester & II. Trimester & III. Trimester & \\
\hline & $\mathrm{X} \pm \mathrm{SS}$ & $\mathrm{X} \pm \mathrm{SS}$ & $\mathrm{X} \pm \mathrm{SS}$ & $\mathbf{p}$ \\
\hline NSP-Toplam & $110,91 \pm 83,40$ & $145,56 \pm 101,88$ & $183,85 \pm 123,60$ & 0,001 \\
\hline NSP-FA & $19,18 \pm 19,99$ & $29,72 \pm 21,90$ & $37,69 \pm 22,19$ & 0,000 \\
\hline NSP-A & $15,88 \pm 17,81$ & $18,64 \pm 21,33$ & $24,39 \pm 23,59$ & 0,080 \\
\hline NSP-ES & $35,78 \pm 36,11$ & $43,97 \pm 38,46$ & $47,36 \pm 38,12$ & 0,242 \\
\hline NSP-U & $21,40 \pm 20,80$ & $24,33 \pm 27,84$ & $29,74 \pm 27,55$ & 0,207 \\
\hline NSP-Sİ & $9,60 \pm 15,96$ & $17,92 \pm 21,92$ & $27,81 \pm 30,25$ & 0,000 \\
\hline NSP-ER & $9,04 \pm 13,99$ & $10,95 \pm 16,48$ & $16,83 \pm 22,72$ & 0,045 \\
\hline UAFA-KF & $516,94 \pm 633,34$ & $1086 \pm 2106,62$ & $585,17 \pm 794,80$ & 0,039 \\
\hline
\end{tabular}

celeyen çalışmalar mevcuttur. Yapılan bu çalışmalar trimesterlere göre aktivite düzeyleri arasında farklı sonuçlar ortaya koymaktadır. Lee ve ark. (21) tarafından yapılan bir çalışmada kadınların sedanter ve mesleki faaliyetler haricindeki toplam fiziksel aktiviteleri ve bu aktivitelerin yoğunlukları ile enerji harcaması gebeliğin ilk trimesterinde diğer dönemlere göre en düşük olarak bulunmuştur. Bulunan bu sonuç bizim çalışmamızla paralellik göstermektedir. İkinci dönemde, toplam fiziksel aktiviteler için medyan enerji harcamasının yanı sıra aktivitelerin yoğunlukları ve sayılarının arttığ 1 ancak meslek ile ilgili aktivite düzeyinin azaldığ 1 sonucuna ulaşılmıştır. Ek olarak, çalışmada son üç aylık dönemde gebe kadınların toplam fiziksel aktivitelerinin medyan enerji harcamasının yanı sıra yoğunlukları ve sayılarının ikinci trimestere göre biraz daha arttığı, ancak mesleki faaliyetlerin daha da azaldığı bulgusunu elde etmişlerdir (21).

Ko ve ark. (3) gebelik boyunca fiziksel aktivitedeki değişiklikleri ve gebelik dönemleri fiziksel aktivite düzeyleri arasındaki ilişkiyi incelemek için yaptıkları çalışmada, katılımcıların gebelik dönemindeki fiziksel aktivitelerinin, gebelik öncesi dönem ile karşılaştırıldığında \%31 oranında azaldığını ve genel fiziksel aktivite seviyelerinin gebelik öncesi dönemden ilk döneme kadar düştüğü, ancak ikinci ve üçüncü trimesterde stabil kaldığı bulgusunu elde etmişlerdir. Gebeliğin ilk trimesteri için elde edilen bu sonuçları, gebeliğin ilk üç ayında kadınların, fetüsün güvenliğini sağlamak için faaliyetlerini azaltma çabasına ve gebeliğin oluş- turduğu fiziksel rahatsızlıklara bağlamışlardır. İkinci trimesterde, kadınların haftalar ilerledikçe gebelik stabilize olurken fiziksel olarak daha aktif olmaya başladığını; üçüncü trimesterde ise kadınların iyi doğum yapmak ve fiziksel aktivitelerini sürdürmek istemeleri nedeniyle aktivite düzeylerinin ilk döneme göre yüksek olduğunu belirtmişlerdir. Çalışmamızda da kadınların gebeliğin ikinci döneminde ilk döneme göre oldukça yüksek fiziksel aktivite düzeyine sahip oldukları görüldü. $\mathrm{Bu}$ durumun gebeliğin ilk dönemindeki sıkıntıları aşmak için kişilerin ihtiyatlı davranmaları ancak haftalar geçtikçe bu sıkıntıların aşılması, gebeliğe adaptasyon ve kendine güvenin artması, aynı zamanda yorgunluk, mide bulantısı ve kusma gibi semptomların azalması nedeniyle gözlendiği düşünülebilir. Gebeliğin üçüncü döneminde çalışmamızda da Ko ve arkadaşlarının (3) sonuçlarına benzer bulgulara ulaşıldı. Üçüncü dönemde gebelerin fiziksel aktivite puanları birinci dönemden bir miktar daha yüksekti. Fakat ikinci döneme göre düşüktü. Üçüncü dönemde vücutta gözlenen değişikliklerin belirginleşmesi fiziksel aktivite düzeyinin ikinci döneme göre oldukça fazla düşüş göstermesinin nedeni olabilir. Literatürde fiziksel aktivite düzeylerini gösteren çalışmalardaki sonuçlar arasındaki farklılıkların kültürel farklardan ve gebeliğe dair inanışlardan kaynaklanabileceğini düşünmekteyiz.

Gebelikte yaşam kalitesini inceleyen çalışmalarda gebelerin gebelik haftası ile yaşam kalitesi arasında ilişki olduğu belirtilmektedir. Bazı çalışmalarda gebelik haftası arttıkça yaşam kalitesinin olumlu yönde 
etkilendiği belirtilirken (26), yaşam kalitesindeki azalmanın gebeliğin ilerleyen evrelerinde daha fazla olduğunu belirten çalışmalar da bulunmaktadır $(2,27)$. Literatürdeki benzer çalışmalarda ise farklı olarak yaşam kalitesinin gebeliğin ilk ve üçüncü trimesterinde ikinci trimestere göre daha düşük olduğu belirtilmektedir $(28,29)$. Aynı zamanda Da Costa ve ark. (30) yaşam kalitesinin özellikle fiziksel alt parametrelerinin gebelikte gözlenebilen uyku problemleri nedeniyle düşük olduğunu ve gebeliğin üçüncü döneminde en düşük düzeyde olduğunu belirtmişlerdir. Çalışmamızda gebelik ilerledikçe gebelerin yaşam kalitelerinin de düştüğü bulundu. Gebelik trimesterlerine göre karşılaştırılma yapıldığında toplam yaşam kalitesi, ağrı, fiziksel aktivite, sosyal izolasyon, emosyonel reaksiyonlar alt parametrelerinde fark olduğu saptandı. Bu farkın ise üçüncü trimesterden kaynaklandığı görüldü. Yani gebelik ilerledikçe kadınların yaşam kalitelerinin de kötüleştiği bulundu. $\mathrm{Bu}$ durumun gebelikte oluşan kilo alımı, günlük aktivitelerini gerçekleştirmede gelişen engeller ve doğumun yaklaşmasına az bir süre kalmasından ötürü gelişen stres ve kaygıdan ve gebelikte yaşanan uyku bozukluğu gibi problemlerin en sık bu dönemde görülmesinden kaynakladığını düşünmekteyiz.

Bunlara ek olarak çalışmalarda fiziksel aktivite düzeyi ile yaşam kalitesi arasında da ilişki olduğu da belirtilmektedir. Haas ve ark. (31) tarafından yapılan çalışmanın sonuçlarına göre ikinci ve üçüncü trimesterdeki gebe kadınların hem fiziksel aktivite hem de yaşam kalitesi algılamalarında düşüş olduğu sonucuna varılmıştır. Kolu ve ark. (32) fiziksel aktivitenin yaşam kalitesi üzerindeki etkisini inceledikleri çalışmada sağlıkla ilgili yaşam kalitesinin fiziksel olarak aktif olan kadınlarda daha az aktif olanlara göre daha yüksek olduğu sonucuna varmışlardır. Buna ilaveten fiziksel olarak gebelik boyunca daha aktif olan kadınların uyku kalitelerinin de daha yüksek olduğu görülmüştür. Benzer şekilde bir başka çalışmada da gebelik boyunca aerobik egzersiz yaparak fiziksel aktivite düzeyini artıran kadınların yaşam kalite düzeylerinde belirgin artış gözlenmiştir (33). Çalışmamızda fiziksel aktivite puanı ile yaşam kalitesi arasında ilişki bulunmazken, fiziksel aktivite seviyesi ile NSP toplam, enerji seviyesi, sosyal izolasyon ve uyku alt parametreleri arasında negatif yönde düşük düzeyde anlamlı bir ilişki olduğu görüldü. Kadınların gebelikte aktivite seviyeleri yükseldikçe yaşam kalitelerinin de arttı̆̆g gözlendi.

Gebelerin gebelik öncesi fiziksel aktivite seviyelerini sorgulayan soruların yöneltilmemesi nedeniyle fiziksel aktivite seviyelerinin belirlenememesi ve gebelik öncesi durumun gebelik sırasındaki fiziksel aktivite düzeyi ile karşılaştırılamaması, gebelerin doğum sırasinda ve sonrası takiplerinin yapılmaması ve fiziksel aktivite seviyesinin bebeğin doğum ağırlığı ve annenin rahat ve kolay doğum yapması üzerindeki etkisinin araştırılmaması çalışmamızın limitasyonları arasında gösterilebilir. Aynı zamanda çalışmada gebelerde fiziksel aktivite düzeyini belirlemek için genel bir fiziksel aktivite anketi kullanılması da çalışmanın bir başka limitasyonu olarak düşünülebilir. Ancak çalışmanın yürütüldüğü sırada Türkçe geçerlilik ve güvenilirliği olan gebelere özgü fiziksel aktivite anketi bulunmamaktayd.

\section{SONUÇ}

Çalışmamızda gebe kadınların fiziksel aktivite seviyesi ile yaşam kalitesi arasında negatif yönde ilişki olduğu sonucuna varıldı. Çalışmada ayrıca gebelik trimesterlerine göre kadınların yaşam kaliteleri incelendiğinde, ilk trimesterden üçüncü trimestere ilerledikçe yaşam kalite düzeylerinde azalma olduğu sonucuna ulaşıldı. Ek olarak, üçüncü trimestere doğru ilerledikçe gebelerin fiziksel aktivite düzeylerinde artma olduğu; özellikle gebeliğin ikinci trimesterinde fiziksel aktivite düzeylerinin ilk ve üçüncü döneme göre oldukça yüksek olduğu sonucuna ulaşıldı.

$\mathrm{Bu}$ çalışma Türk popülasyonunda gebelerde fiziksel aktivitenin değerlendirildiği ve fiziksel aktivite ile yaşam kalitesi arasındaki ilişkinin incelendiği ilk pilot çalışma olması bakımından önem taşımaktadır. Fiziksel aktivite seviyesini artırmanın gebelikte anne ve çocuk sağllğ 1 üzerinde olumlu etkileri olduğu bilinmektedir. Daha geniş örneklemler üzerinde, gebelerde fiziksel aktiviteyi değerlendiren gebeliğe özgü bir fiziksel aktivite anketi kullanılarak gerçekleştirilecek çalışmalara ihtiyaç olduğu düşüncesindeyiz. 


\section{KAYNAKLAR}

1. WHO. Physical activity. Erişim: http://www.who.int/ mediacentre/factsheets/fs385/en/, erişim tarihi: 3 Mart 2017.

2. Warburton DE, Nicol CW, Bredin SS. Health benefits of physical activity: the evidence. Can Med Assoc J. 2006;174(6):801-9.

3. Ko Y-L, Chen C-P, Lin P-C. Physical activities during pregnancy and type of delivery in nulliparae. Eur J Sport Sci. 2016;16(3):374-80.

4. Aune D, Saugstad OD, Henriksen T, Tonstad S. Physical activity and the risk of preeclampsia: a systematic review and meta-analysis. Epidemiology. 2014;25(3):331-43.

5. Moore SC, Patel AV, Matthews CE, de Gonzalez AB, Park Y, Katki HA ve ark. Leisure time physical activity of moderate to vigorous intensity and mortality: a large pooled cohort analysis. PLoS Med. 2012;9(11):e1001335.

6. Khan T, Macaulay S, Norris SA, Micklesfield LK, Watson ED. Physical activity and the risk for gestational diabetes mellitus amongst pregnant women living in Soweto: a study protocol. BMC Womens Health. 2016;16(1):66.

7. Kasawara KT, Nascimento SL, Costa ML, Surita FG, Silva E, Pinto JL. Exercise and physical activity in the prevention of pre-eclampsia: systematic review. Acta Obstet Gyn Jpn. 2012;91(10):1147-57.

8. Ruchat SM, Mottola MF. The important role of physical activity in the prevention and management of gestational diabetes mellitus. Diabetes Metab Res. 2013;29(5):334-46.

9. Nascimento SL, Surita FG, Cecatti JG. Physical exercise during pregnancy: a systematic review. Curr Opin in Obstet Gyn. 2012;24(6):387-94.

10. Guszkowska M, Langwald M, Dudziak D, Zaremba A. Influence of a single physical exercise class on mood states of pregnant women. J Psychosom Obst Gyn. 2013;34(2):98-104.

11. Evenson KR, Siega-Riz AM, Savitz DA, Leiferman JA, Thorp Jr JM. Vigorous leisure activity and pregnancy outcome. Epidemiology. 2002;13(6):653-9.

12. Aittasalo M, Pasanen M, Fogelholm M, Kinnunen TI, Ojala K, Luoto R. Physical activity counseling in maternity and child health care-a controlled trial. BMC Womens Health. 2008;8(1):14.

13. Davies GA, Wolfe LA, Mottola MF, MacKinnon C. Joint SOGC/CSEP clinical practice guideline: exercise in pregnancy and the postpartum period. Can J Appl Physiol. 2003;28(3):329-41.

14. Amezcua-Prieto C, Olmedo-Requena R, Jímenez-Mejías E, Hurtado-Sánchez F, Mozas-Moreno J, Lardelli-Claret
P ve ark. Changes in leisure time physical activity during pregnancy compared to the prior year. Matern Child Health J. 2013;17(4):632-8.

15. Chasan-Taber L, Schmidt MD, Pekow P, Sternfeld B, Manson J, Markenson G. Correlates of physical activity in pregnancy among Latina women. Matern Child Health J. 2007;11(4):353-63.

16. Clarke P, Rousham E, Gross H, Halligan A, Bosio P. Activity patterns and time allocation during pregnancy: a longitudinal study of British women. Ann Hum Biol. 2005;32(3):247-58.

17. Oken E, Ning Y, Rifas-Shiman SL, Radesky JS, RichEdwards JW, Gillman MW. Associations of physical activity and inactivity before and during pregnancy with glucose tolerance. Obstet Gynecol. 2006;108(5):1200.

18. Rousham E, Clarke P, Gross H. Significant changes in physical activity among pregnant women in the UK as assessed by accelerometry and self-reported activity. Eur J Clin Nutr. 2006;60(3):393-400.

19. Tung CT, Lee CF, Lin SS, Lin HM. The exercise patterns of pregnant women in Taiwan. J Nurs Res. 2014;22(4):242-9.

20. Zhang Y, Dong S, Zuo J, Hu X, Zhang H, Zhao Y. Physical activity level of urban pregnant women in Tianjin, China a cross-sectional study. PloS One. 2014;9(10):e109624.

21. Lee CF, Hwang FM, Lin HM, Chi LK, Chien LY. The physical activity patterns of pregnant Taiwanese women. J Nurs Res. 2016;24(4):291-9.

22. Hueston WJ, Kasik-Miller S. Changes in functional health status during normal pregnancy. J Fam Pract. 1998,47(3);209-13

23. Ünver H. Gebelerde Egzersizin Yaşam Kalitesi Üzerine Etkisi [yüksek lisans tezi]. Malatya: İnönü Üniversitesi; 2014.

24. Kücükdeveci A, McKenna S, Kutlay S, Gürsel Y, Whalley $\mathrm{D}$, Arasil T. The development and psychometric assessment of the Turkish version of the Nottingham Health Profile. Int J Rehabil Res. 2000;23(1):31-8.

25. Saglam M, Arikan H, Savci S, Inal-Ince D, Bosnak-Guclu M, Karabulut E ve ark. International physical activity questionnaire: reliability and validity of the Turkish version. Percept Motor Skill. 2010;111(1):278-84.

26. Arabacıoğlu C. Gebelerde Yaşam Kalitesi ve Eğitim Gereksinimlerinin Belirlenmesi [yüksek lisans tezi]. İstanbul: İstanbul Bilim Üniversitesi; 2012.

27. Global Recommendations on Physical Activity for Health. World Health Organization; 2010.

28. Özçelik G. Aydın İlinde Gebelikte Yaşanan Sağlık Sorunları ve Yaşam Kalitesi ile İlişkisi [yüksek lisans tezi]. Aydın: Adnan Menderes Üniversitesi; 2010. 
29. Kılıçarslan S. Edirne Şehir Merkezindeki Son Trimester Gebelerin Sosyodemografik Özellikleri, Yaşam Kaliteleri, Kayg 1 Düzeyleri [uzmanlık tezi]. Edirne: Trakya Üniversitesi; 2008.

30. Da Costa D, Dritsa M, Verreault N, Balaa C, Kudzman J, Khalifé S. Sleep problems and depressed mood negatively impact health-related quality of life during pregnancy. Arch Womens Ment Health. 2010;13(3):249-57.

31. Haas JS, Jackson RA, Fuentes-Afflick E, Stewart AL, Dean ML, Brawarsky P ve ark. Changes in the health status of women during and after pregnancy. J Gen Intern Med. 2005;20(1):45-51.
32. Kolu P, Raitanen J, Luoto R. Physical activity and healthrelated quality of life during pregnancy: a secondary analysis of a cluster-randomised trial. Matern Child Health J. 2014;18(9):2098-105.

33. Arizabaleta AVM, Buitrago LO, de Plata ACA, Escudero MM, Ramírez-Vélez R. Aerobic exercise during pregnancy improves health-related quality of life: a randomised trial. J Physiother. 2010;56(4):253-8. 